
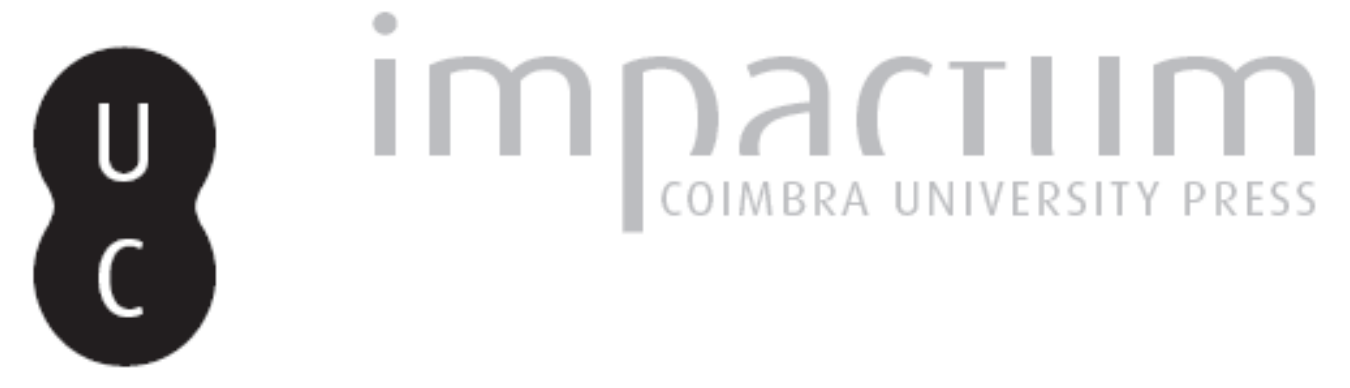

\title{
Verificação da segurança de estruturas marítimas utilizando métodos probabilísticos de níveis II e III
}
Autor(es):
Reis, Maria Teresa; Santos, João Alfredo
Publicado por: Associação Portuguesa de Riscos, Prevenção e Segurança
URL persistente:
URI:http://hdl.handle.net/10316.2/36049
DOI:
DOI:http://dx.doi.org/10.14195/1647-7723_18_6
Accessed :
26-Apr-2023 07:41:53

A navegação consulta e descarregamento dos títulos inseridos nas Bibliotecas Digitais UC Digitalis, UC Pombalina e UC Impactum, pressupõem a aceitação plena e sem reservas dos Termos e Condições de Uso destas Bibliotecas Digitais, disponíveis em https://digitalis.uc.pt/pt-pt/termos.

Conforme exposto nos referidos Termos e Condições de Uso, o descarregamento de títulos de acesso restrito requer uma licença válida de autorização devendo o utilizador aceder ao(s) documento(s) a partir de um endereço de IP da instituição detentora da supramencionada licença.

Ao utilizador é apenas permitido o descarregamento para uso pessoal, pelo que o emprego do(s) título(s) descarregado(s) para outro fim, designadamente comercial, carece de autorização do respetivo autor ou editor da obra.

Na medida em que todas as obras da UC Digitalis se encontram protegidas pelo Código do Direito de Autor e Direitos Conexos e demais legislação aplicável, toda a cópia, parcial ou total, deste documento, nos casos em que é legalmente admitida, deverá conter ou fazer-se acompanhar por este aviso.

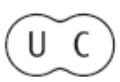




\section{territorium}

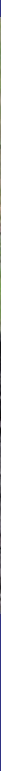

\section{Afirmar as Ciências Cindínicas}

Revista da Associação Portuguesa de Riscos, Prevenção e Segurança 
Maria Teresa Reis

Núcleo de Portos e Estruturas Marítimas, Departamento de Hidráulica e Ambiente, Laboratório Nacional de Engenharia Civil, treis@lnec.pt

João Alfredo Santos

Núcleo de Portos e Estruturas Marítimas, Departamento de Hidráulica e Ambiente, Laboratório Nacional de Engenharia Civil, jasantos@lnec.pt

\section{RESUMO}

Este artigo ilustra o trabalho que o Núcleo de Portos e Estruturas Marítimas do LNEC tem vindo a desenvolver no âmbito da verificação da segurança à estabilidade e ao galgamento de estruturas marítimas utilizando métodos probabilísticos de níveis II e III. Apresentam-se dois casos de estudo: 1) verificação da segurança ao modo de falha por galgamento de uma estrutura de protecção costeira; e 2) verificação da segurança ao modo de falha por instabilidade hidráulica do manto protector de um quebra-mar de taludes.

Palavras chave: Estruturas marítimas, estabilidade, galgamentos, verificação da segurança, métodos probabilísticos de níveis II e III.

\section{RESUMEN}

Verificación de la Seguridad de Estructuras Marítimas Utilizando Métodos Probabilistas de Nivel II y III - En este artículo se ilustra el trabajo que el Núcleo de Puertos y Estructuras Marítimas del LNEC viene desarrollando en el cuadro de la verificación de la seguridad de estructuras marítimas a la estabilidad e rebase utilizando métodos probabilistas de nivel II y IIII. Se presentan dos casos de estudio: 1) verificación de la seguridad al modo de fallo por rebase de una estructura de protección costera; y 2) verificación de la seguridad al modo de fallo por inestabilidad hidráulica del manto protector de un dique en talud.

Palabras clave: Estructuras marítimas, estabilidad, rebase, verificación de la seguridad, métodos probabilistas de nivel II y III.

\section{RESUMÉ}

Vérification de la Sécurité de Structures Maritimes par des Méthodes Probabilistes de Niveaux II et III - Cet article illustre le travaille que la Division de Ports et Structures Maritimes du LNEC a développé dans le cadre de la vérification de la sécurité de la stabilité et du débordement de structures maritimes en utilisant des méthodes probabilistes de niveaux II et III. Deux cas sont présentés: 1) vérification de la sécurité au mode de rupture par débordement de une structure de protection côtière; et 2) vérification de la sécurité au mode de rupture par instabilité hydraulique du manteau protecteur d'un brise mer.

Mots-clé: Structures maritimes, stabilité, débordement, vérification de sécurité, méthodes probabilistes de niveaux II et III.

\section{ABSTRACT}

Probabilistic Assessment of the Safety of Sea Defences Using Level II and Level III Methods - This paper illustrates the work that the Harbours and Maritime Structures Division of LNEC has been developing on the assessment of the safety of sea defences with respect to their armour stability and wave overtopping using level II and level III methods. Two case studies are shown: 1) safety assessment regarding the failure mode of wave overtopping of a seawall; and 2) safety assessment regarding the failure mode of armour layer instability of a rubble mound breakwater.

Key words: Sea defences, armour stability, wave overtopping, safety assessment, probabilistic methods of level II and level III.

* O texto deste artigo corresponde à comunicação apresentada ao II Congresso Internacional de Riscos e VI Encontro Nacional, tendo sido submetido para revisão em 28-05-2010, tendo sido aceite para publicação em 29-07-2010.

Este artigo é parte integrante da Revista Territorium, n. ${ }^{\circ} 18,2011$, ${ }^{\circledR}$ RISCOS, ISBN: 0872- 8941. 
Introdução

A sociedade em geral, bem como as normas para o projecto, construção e manutenção de estruturas, nas quais se podem incluir as estruturas marítimas, exigem, cada vez mais, uma quantificação dos riscos e um aumento da fiabilidade daquelas estruturas. Por outro lado, numa era de aquecimento global, subida de nível do mar e aumento de ocorrência de temporais, cujas consequências podem incluir um aumento das solicitações nas estruturas, a gestão de riscos é uma ferramenta com crescente aplicação para apoio à decisão.

Os procedimentos convencionais de dimensionamento e de verificação da segurança de estruturas marítimas não se baseiam numa avaliação de riscos explícita e sistemática, sendo essencialmente de natureza determinística. Isto apesar da complexidade e do custo destas estruturas e das inúmeras incertezas que estão associadas quer ao carácter aleatório das solicitações actuantes (e.g. ondas, correntes), quer aos modelos utilizados para representar a realidade (e.g. modelos físicos/numéricos). As recomendações existentes para o projecto, construção e manutenção deste tipo de estruturas já incluem abordagens de gestão de riscos, baseadas em métodos probabilísticos e de optimização (e.g. Puertos Del Estado, 2002; USACE, 2003; CIRIA/CUR/CETMEF, 2007). No entanto estas abordagens não foram ainda totalmente implementadas na prática corrente, apesar de os métodos determinísticos actualmente disponíveis serem desadequados a uma prática de engenharia que se pretende rigorosa e sustentada pelo conhecimento e interpretação científica da realidade.

Este artigo ilustra o trabalho que o Núcleo de Portos e Estruturas Marítimas do Departamento de Hidráulica e Ambiente do Laboratório Nacional de Engenharia Civil (LNEC) tem vindo a desenvolver no âmbito da verificação da segurança à estabilidade e ao galgamento de estruturas marítimas utilizando métodos probabilísticos de níveis II e III. Assim, depois da Introdução, apresentam-se sucintamente os métodos probabilísticos existentes para dimensionamento e verificação da segurança. Seguidamente, descreve-se brevemente os pacotes numéricos de cálculo probabilístico utilizados, PARASODE-BALI (M. T. ReIs, 1998; I. A. SousA et al., 2005) e @Risk (PALISADE CORPORATION, 1994, 2002). Nas secções seguintes são apresentados dois casos de estudo: i) verificação da segurança ao modo de falha por galgamento de uma estrutura de protecção costeira; e ii) verificação da segurança ao modo de falha por instabilidade hidráulica do manto protector de um quebra-mar de taludes. Por fim, a última secção contém as considerações finais do trabalho.

\section{Análise Probabilística de um Modo de Falha}

Começando por estudar um modo de falha isoladamente, isto é, assumindo que outros modos de falha não têm influência no modo em estudo, expressões teóricas ou fórmulas empíricas podem ser utilizadas para definir uma função de falha $Z=Z(X)$ envolvendo as variáveis $X=\left[X_{1}, \ldots, X_{N}\right]$ relevantes para esse modo de falha. $Z$ toma valores positivos na ausência de falha e valores negativos ou nulos caso contrário. A superfície definida por $\mathrm{Z}=0$ designa-se por superfície de falha. As variáveis $X_{i}$ cujo crescimento implica o crescimento de $Z$ designam-se por variáveis de resistência enquanto aquelas cujo aumento provoca um decréscimo do valor de $\mathrm{Z}$ são designadas por variáveis de solicitação.

Como algumas destas variáveis, sejam elas de resistência ou de solicitação, podem ter um carácter aleatório (algumas até podem estar correlacionadas entre si), aquela função define uma variável aleatória, correspondendo então a probabilidade de falha, $P_{f}$, à obtenção de valores de $\mathrm{Z}$ menores ou iguais a zero, isto é:

$$
P_{f}=P(Z \leq 0)=\int_{Z \leq 0} f_{X}(X) d X
$$

em que $f_{x}$ é a densidade de probabilidade conjunta das variáveis $\mathrm{X}=\left[\mathrm{X}_{1}, \ldots, \mathrm{X}_{\mathrm{N}}\right]$.

É a forma de calcular a probabilidade de falha que distingue os vários níveis dos métodos probabilísticos existentes para dimensionamento e verificação da segurança. Com efeito, excepto em casos com funções de falha muito simples e com um número muito baixo de variáveis de solicitação e resistência, a integração múltipla da eq. (1) não se pode realizar analiticamente e tem que ser aproximada através de métodos de cálculo mais simples.

Distinguem-se normalmente na literatura três níveis de cálculo, consoante o tipo de aproximações feitas e o tipo de cálculo empregue. Por ordem decrescente de precisão e complexidade esses níveis de cálculo são:

- Nível III - a probabilidade de falha é calculada de forma "exacta" a partir da função densidade de probabilidade conjunta das variáveis de solicitação e de resistência, incluindo as correlações entre elas. Os métodos de nível III mais usados recorrem a técnicas de amostragem, devido à complexidade dos integrais envolvidos no cálculo da probabilidade de falha.

- Nível II - as variáveis correlacionadas e/ou não-normais são transformadas em variáveis independentes e normais tendo, no entanto, em consideração a sua caracterização original no processo de transformação. As funções de falha são aproximadas por um plano tangente a um dado ponto ou por um polinómio de grau superior. Com estas aproximações e atendendo às propriedades das variáveis aleatórias normais, torna-se muito mais simples o cálculo da probabilidade de falha. 
- Nível I - em vez das distribuições correspondentes às variáveis de solicitação e de resistência utilizam-se valores característicos destas variáveis que, consoante o tipo de variável, serão multiplicados (variáveis de solicitação) ou divididos (variáveis de resistência) por coeficientes de segurança. Os valores resultantes são introduzidos na função de falha para se confirmar que o valor obtido é positivo.

A principal vantagem dos métodos de nível II relativamente aos de nível III é não requererem uma capacidade de cálculo muito elevada e esta ser independente do valor da probabilidade de falha. Os métodos de nível II têm também constituído frequentemente a base para a fixação dos coeficientes de segurança utilizados nos métodos de nível I. Para além disso, na execução dos métodos de nível II, está implícita a determinação da sensibilidade da probabilidade de falha calculada a cada variável de solicitação e resistência, o que permite ao utilizador concentrar a sua atenção na definição das variáveis que maior influência têm no resultado obtido.

Nos casos de estudo apresentados, utilizam-se os pacotes numéricos PARASODE-BALI (M. T. ReIS, 1998; I. A. SousA et al., 2005) e @Risk (PALISADE CORPORATION, 1994, 2002), nos quais estão implementados os métodos de níveis II e III, respectivamente. Detalhes sobre estes métodos podem encontrar-se na literatura (e.g. M. T. REIS, 1998).

\section{Pacotes Numéricos Utilizados}

\section{PARASODE-BALI}

PARASODE-BALI (Probabilistic Assessment of $\underline{\text { Risks }}$

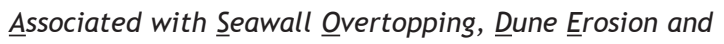

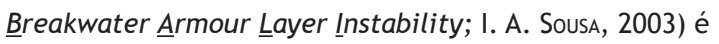
uma extensão do pacote numérico PARASODE (M. T. REIS, 1998) que se baseia em métodos probabilísticos de nível II, mais precisamente no método conhecido por First Order Reliability Method (FORM). Tal como o nome indica, PARASODE-BALI concentra-se em três modos de falha. No entanto, a maioria do código é de aplicação genérica, pelo que pode ser adaptado com facilidade para o estudo de outros modos de falha.

PARASODE-BALI possui dois modos de funcionamento (fig. 1):

\section{- Modo de verificação da segurança de estruturas} já existentes - dado o valor do parâmetro de dimensionamento (por exemplo, a altura de coroamento de uma protecção marginal ou o diâmetro nominal dos elementos do manto de um quebra-mar) e os das restantes características do problema, compara-se o valor correspondente da probabilidade de falha com o considerado admissível;
- Modo de dimensionamento de novas estruturas calcula-se o valor do parâmetro de dimensionamento, fixadas as restantes características do problema, para que o valor da probabilidade de falha seleccionado não seja excedido.

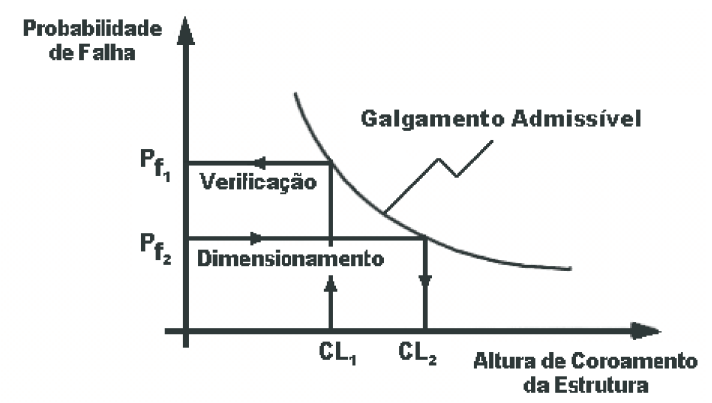

Fig. 1 - Modos de funcionamento do PARASODE-BALI (ilustrados para o modo de falha por galgamento de uma protecção marginal).

O programa incorpora rotinas para transformar as variáveis não-normais e correlacionadas em variáveis normais equivalentes e independentes. A transformação de variáveis não-normais em variáveis de distribuições normais equivalentes é feita de forma que os valores da função densidade de probabilidade e da função de distribuição se mantenham inalterados no ponto $X$ onde se calcula o valor da função de falha, $Z(X)$ (R. RAckwITZ e B. Fiessler, 1978). A transformação de variáveis correlacionadas em variáveis independentes é feita segundo o método apresentado em CIRIA (1984): os valores das variáveis independentes são uma função linear do valor das variáveis correlacionadas e resultam do produto destas pela transposta dos vectores próprios da matriz de covariância das mesmas. De notar que PARASODE-BALI permite a especificação pelo utilizador de um coeficiente de correlação não-nulo entre quaisquer duas variáveis. Um coeficiente de correlação nulo garante a independência entre duas variáveis.

PARASODE-BALI tem incluído no seu código a definição de dez distribuições contínuas: normal, normal logarítmica, Gumbel, uniforme, Gamma, Beta, Frechet, exponencial, Rayleigh e Weibull. Cada distribuição pode ser truncada acima ou abaixo de um determinado valor segundo o método apresentado em G. P. BeAumont (1986).

As variáveis aleatórias podem ainda ser descritas por distribuições empíricas, definidas pelo utilizador e que resultam de medições de uma grandeza que não se preste a ser modelada pelas distribuições pré-definidas.

O código PARASODE-BALI foi escrito em FORTRAN 77 e foi amplamente testado, quer com exemplos da literatura, quer com outros programas semelhantes. Os resultados foram sempre muito satisfatórios (M. T. REIS, 1998).

A validação dos resultados obtidos pelo PARASODE-BALI relativos ao modo de falha por galgamento foi levada a 
cabo utilizando o software comercial @RISK (PALISADE CORPORATION, 1994, 2002) que utiliza cálculos probabilísticos de nível III, mais concretamente técnicas de amostragem.

\section{Modo de falha por galgamento no PARASODE-BALI}

O modo de falha por galgamento de protecções marginais encontra-se implementado no PARASODE-BALI através das fórmulas de Hedges e Reis (T. S. HEDGES e M. T. REIS, 1998, 2004), de Van der Meer e Janssen (J. W. VAN DER Meer e J. P. F. M. Janssen, 1995) e de Owen (M. W. Owen, 1980, 1983; P. BESLEY, 1999). Um dos principais factores que contribui para o grau de confiança associado aos galgamentos determinado por métodos probabilisticos é a fórmula de galgamentos utilizada para descrever falha. Com o objectivo de ilustrar a importância deste factor, as fórmulas de Hedges e Reis e de Van der Meer e Janssen são aplicadas no primeiro caso de estudo apresentado. As funções de falha correspondentes são:

Hedges e Reis (H\&R):

$$
\left\{\begin{array}{lll}
Z=Q-A \cdot \sqrt{g \cdot\left(C \cdot H_{s}\right)^{3}} \cdot\left[1-\frac{C L-S W L}{r . C . H_{S}}\right]^{e_{B} B} & \text { para } & 0 \leq\left[\frac{C L-S W L}{r \cdot C \cdot H_{S}}\right]<1 \\
Z=Q & \text { para } & {\left[\frac{C L-S W L}{r . C \cdot H_{S}}\right] \geq 1}
\end{array}\right.
$$

Van der Meer e Janssen:

$$
\begin{cases}Z=Q-\frac{0.06 \xi_{p} \cdot \sqrt{g \cdot H_{s}^{3}}}{\sqrt{\tan \alpha}} \cdot \operatorname{EXP}\left[-A \cdot \frac{C L-S W L}{r \xi_{p} \cdot H_{s}}\right] & \text { para } \xi_{p} \leq 2 \\ Z=Q-0.2 \sqrt{g \cdot H_{s}^{3}} \cdot \operatorname{EXP}\left[-B \cdot \frac{C L-S W L}{r \cdot H_{s}}\right] & \text { para } \xi_{p}>2\end{cases}
$$

em que:

\section{A e B - coeficientes empíricos;}

Q - caudal médio galgado por unidade de comprimento da estrutura (fig. 2);

$\xi_{p}$ - número de Iribarren, $\xi_{p}=\tan \alpha / \sqrt{2 \pi \cdot H_{s} / g T_{p}^{2}}$;

$\alpha$ - ângulo do talude exterior com o plano horizontal (fig. 2);

$\mathrm{H}_{\mathrm{s}}$ - altura significativa da agitação marítima incidente na estrutura (fig. 2);

$T_{p}$ - período de pico do espectro da agitação marítima incidente na estrutura (fig. 2);

g - aceleração da gravidade;

$r$ - coeficiente que procura reflectir a influência da rugosidade no espraiamento (T. S. Hedges e M. T. REIS, 2004), definindo-se espraiamento como o nível máximo acima do nível de repouso atingido por uma onda num talude;

CL-SWL - altura de coroamento da estrutura (CL) acima do nível de repouso da superfície livre (SWL) e designada neste artigo por folga (fig. 2);
(CL-SWL)/r - a altura de coroamento efectiva quando o talude exterior é rugoso.

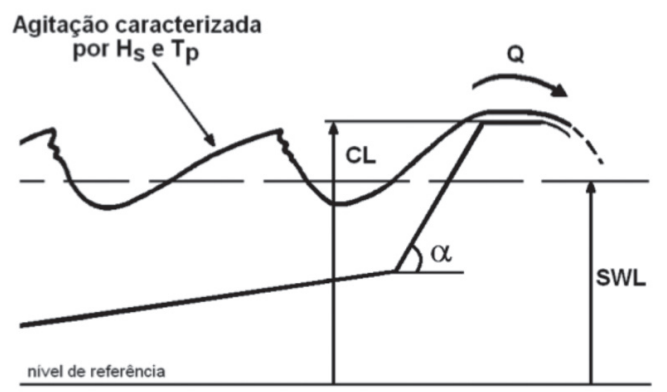

Fig. 2 - Notação.

$\mathrm{Na}$ fórmula $H \& R, \mathrm{e}_{\boldsymbol{B}}$ é um parâmetro que pretende incorporar a fiabilidade da fórmula e C representa o quociente entre o valor máximo observado dos espraiamentos num talude não rugoso durante uma dada tempestade $\left(R_{\max }\right)$ e a altura significativa das ondas incidentes $\left(\mathrm{C}=\mathrm{R}_{\max } / \mathrm{H}_{\mathrm{s}}\right)$. O valor de $\mathrm{R}_{\max }$ não é conhecido previamente sendo, por isso, necessário estimar o seu valor. T. S. Hedges e M. T. ReIs $(1998,2004)$ sugerem que $C$ seja calculado assumindo que a distribuição de Rayleigh é aplicável aos espraiamentos e usando o valor de $R_{\max }$ não excedido em $37 \%$ ou $99 \%$ das tempestadas representadas por 100 ondas:

$$
\begin{array}{lrl}
\frac{\left(R_{\max }\right)_{37 \%, 100}}{H_{s}}=2.05 \xi_{p} & \text { para } 0<\xi_{p}<2 \\
\frac{\left(R_{\max }\right)_{37 \%, 100}}{H_{s}}=4.56-0.23 \xi_{p} & \text { para } 2<\xi_{p}<9 \\
\frac{\left(R_{\max }\right)_{99 \%, 100}}{H_{s}}=2.90 \xi_{p} & \text { para } 0<\xi_{p}<2 \\
\frac{\left(R_{\max }\right)_{99 \%, 100}}{H_{s}}=6.45-0.325 \xi_{p} & \text { para } 2<\xi_{p}<9
\end{array}
$$

Se a distribuição de Rayleigh for aplicável a espraiamentos, então $\left(R_{\max }\right)_{37 \%, 100}=R_{1 \%}$, em que $\mathrm{R}_{\mathrm{n} \%}$ representa o valor excedido por $n \%$ de todos os espraiamentos. Vale a pena referir que, no passado, as estruturas de protecção marítima na Europa continental eram muitas vezes dimensionadas com uma folga igual a $R_{2 \%}$. Segundo a distribuição de Rayleigh, $\left(R_{\max }\right)_{37 \%, 100}$ é aproximadamente $8.5 \%$ superior a $R_{2 \%}$. Numa aproximação mais conservadora, os projectistas podem querer estimar $\mathrm{R}_{\max }$ através de $\left(R_{\max }\right)_{99 \%, 100}=\left(R_{\max }\right)_{37 \%, 10000}=R_{0.01 \%}$.

No caso de regimes de agitação que resultam da acção conjunta de vagas (wind-sea) e ondulação (swell), que são usualmente definidos por um espectro com dois picos distintos, as fórmulas de galgamentos H\&R e de Van der Meer e Janssen podem usar a altura significativa conjunta de onda incidente, Hs, dada por (T. S. Hedges e M. SHAREEF, 2003):

$$
H_{s}=4 \sqrt{m_{0(w)}+m_{0(s)}}=\sqrt{{H_{s(w)}{ }^{2}+H_{s(s)}^{2}}^{2}}
$$


em que $\mathrm{m}_{\mathrm{o}(\mathrm{w})}$ é o momento de ordem zero (ou área) do espectro associado às vagas, $\mathrm{m}_{\mathrm{o(s)}}$ é o momento de ordem zero (ou área) do espectro associado à ondulação, $\mathrm{H}_{\mathrm{s}(\mathrm{w})}$ é a altura significativa associada às vagas e $\mathrm{H}_{\mathrm{s}(\mathrm{s})}$ é a altura significativa associada à ondulação. Para o caso do período, as duas fórmulas de galgamentos utilizam um "período de pico equivalente", $\mathrm{T}_{\mathrm{p}(\mathrm{eq})}$, definido por J. W. VAn der Meer e J. P. F. M. Janssen (1995) da seguinte forma:

$$
T_{p(e q)}=\sqrt[4]{\frac{m_{0(w)}}{m_{0}} \cdot T_{p(w)}{ }^{4}+\frac{m_{0(s)}}{m_{0}} \cdot T_{p(s)}}
$$

na qual $m_{0}=m_{0(w)}+m_{0(s)}, T_{p(w)}$ é o período de pico do espectro associado às vagas $\mathrm{T}_{\mathrm{p}(\mathrm{s})}$ é o período de pico do espectro associado à ondulação.

No caso da acção conjunta de vagas e de ondulação, os valores de $\mathrm{H}_{\mathrm{s}}$ e $\mathrm{T}_{\mathrm{p}}$ necessários para o cálculo das eqs. (2) e (3) são substituídos pelos valores obtidos através das eqs. (6) e (7), respectivamente, e $\xi_{p}$ é substituído por $\xi_{\mathrm{p}(\mathrm{eq})}$ :

$$
\xi_{p(e q)}=\tan \alpha / \sqrt{2 \pi \cdot H_{s} / g T_{p(e q)}{ }^{2}}
$$

As protecções marginais são dimensionadas de forma a limitarem os galgamentos a determinados valores pré-estabelecidos, Q. A fig. 3 mostra valores críticos do caudal médio de galgamentos que são muitas vezes utilizados no projecto de protecções marginais. Com estes valores pretende-se garantir não só a segurança da própria estrutura galgada, mas também a dos peões e veículos que utilizem a estrutura ou que se encontrem nas suas proximidades. Pretende-se ainda evitar estragos nos edifícios localizados na zona abrigada pela estrutura.

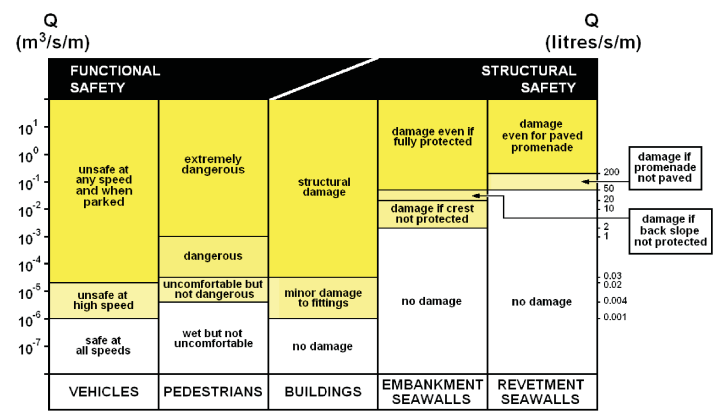

Fig. 3 - Valores críticos do caudal médio de galgamentos (adaptado de CIRIA/CUR, 1991).

Merecedora de destaque na fig. 3 é a gama crítica de caudais médios por comprimento unitário da estrutura, $\mathrm{Q}$, que vai desde valores tão pequenos como $0.001 \mathrm{l} / \mathrm{s} / \mathrm{m}$ até aproximadamente $200 \mathrm{l} / \mathrm{s} / \mathrm{m}$. A relevância destes valores limites tornar-se-á evidente no primeiro caso de estudo apresentado.

A falha por galgamento de uma protecção marginal ocorre quando o caudal médio que galga o coroamento da estrutura excede o valor do caudal médio de galgamentos admissivel. A probabilidade de falha aceitável depende das consequências da ocorrência dos galgamentos excessivos. O risco associado aos galgamentos define-se como o produto da probabilidade de falha pelo custo associado às mesmas consequências. Apresenta-se em M. T. Reis et al. (2005) o resultado de um inventário das consequências da ocorrência de galgamentos de estruturas marítimas. Nos casos em que os galgamentos possam causar vítimas mortais (e.g. pessoas atingidas por massas de água e arrastadas para o mar), a probabilidade de falha aceitável é muito pequena. Por outro lado, se as consequências se limitam, por exemplo, a pequenos estragos em jardins ou ao fecho temporário de uma estrada secundária, então a probabilidade de falha aceitável poderá ser bastante superior.

Para protecções marginais, probabilidades de falha anuais aceitáveis variam frequentemente entre $0.01 \%$ e $1 \%$, mas poderão ser superiores quando se consideram apenas requisitos de segurança funcional da estrutura. No primeiro caso de estudo apresentado, as probabilidades de falhas anuais consideradas admissíveis variam entre estes dois valores. Assumindo que estes valores da probabilidade de falha anual se mantêm constantes ao longo do tempo e que os acontecimentos em anos consecutivos são independentes entre si, é possível calcular a probabilidade de determinado valor admissível de galgamentos previamente especificado ser excedido ao longo de períodos de tempo, $\mathrm{T}_{\text {ref }}$, superiores ao ano:

$$
P\left(Z \leq 0 ; T_{\text {ref }}\right)=1-[1-P(Z \leq 0 ; 1 \text { ano })]^{T_{\text {ref }}}
$$

Consequentemente, os dois valores de probabilidade de falha mencionados anteriormente implicam que, para um período de 50 anos, a probabilidade de falha varia aproximadamente entre $0.5 \%$ e $40 \%$, respectivamente.

\section{@RISK}

O software @RISK é comercializado pela PALISADE CORPORATION (2002) e o seu objectivo é possibilitar aos utilizadores do Microsoft Excel a realização de cálculo probabilístico de nível III, mais concretamente, através das técnicas de amostragem de Monte Carlo e de Latin Hypercube Sampling (LHS).

Para que seja possível proceder-se à implementação de um método de amostragem (seja o Monte Carlo, o LHS, ou outro) é necessário ter-se um gerador de números aleatórios. A série de amostras geradas aleatoriamente utilizada pelo @RISK (e que constitui uma simulação) começa, por omissão, num valor escolhido ao acaso. No entanto, há situações em que se torna vantajoso testar repetidas vezes a mesma série de valores aleatórios. 0 @RISK também permite esta opção. Executar várias 
simulações utilizando a mesma série de amostras, mudando apenas a caracterização de umas das variáveis aleatórias, permite esclarecer a influência dessa variável aleatória nos resultados, desprezando assim a influência da eficácia do gerador de números aleatórios ou do número de amostras da simulação. O @RISK permite a utilização de um número virtualmente ilimitado de amostras por simulação.

A forma como o @RISK funciona é em tudo semelhante ao Excel e como tal, familiar a muitos utilizadores. No cálculo de probabilidades de falha com o @RISK há que:

- Introduzir numa célula do Excel a expressão da função de falha;

- Utilizar as distribuições probabilísticas disponíveis (mais de 30) para modelar as variáveis intervenientes na função de falha que têm carácter aleatório (caso nenhuma das distribuições disponíveis se revele adequada é ainda possível ao utilizador definir a distribuição desejada);

- Definir a correlação entre as variáveis intervenientes na função de falha (@RISK permite, por exemplo, a definição de uma matriz de correlação entre as variáveis intervenientes);

- Proceder à simulação definindo qual o número de amostras a realizar e qual o método de amostragem a utilizar (Monte Carlo ou LHS).

A análise de resultados é bastante simples. O @RISK possibilita ao utilizador visualizar os resultados, quer sob a forma gráfica, quer sob a forma numérica. Isto é possível não só para as variáveis intervenientes na função de falha (para verificar se as distribuições probabilísticas que modelam as variáveis de entrada são bem reproduzidas pelas amostras geradas durante a simulação), mas também para as probabilidades de falha calculadas (o quociente entre o número de amostras em que o valor da função de falha assume um valor negativo ou nulo e o número de amostras realizadas).

\section{Modo de falha por instabilidade do manto no @RISK}

O escoamento associado às ondas marítimas incidentes num quebra-mar de taludes pode promover a remoção de elementos do manto protector do quebra-mar originando aquilo que se designa pela instabilidade hidráulica do manto. Uma medida dessa instabilidade pode ser fornecida pelo dano do manto protector, $\mathrm{S}$, definido como o quociente entre a área erodida do perfil transversal inicial da estrutura logo após a construção e o quadrado do diâmetro nominal mediano dos elementos do manto protector do quebra-mar, $D_{n 50}{ }^{2}$. Diz-se que o manto falhou quando a camada subjacente ao mesmo fica visível numa área equivalente a $D_{n 50}{ }^{2}$. Os resultados experimentais mostraram que tal corresponde a um valor médio do dano acumulado igual a 8 .

J. A. MelBy (1999) apresenta uma fórmula para a evolução do dano que resultou de um conjunto de ensaios de longa duração com um modelo reduzido de um quebra-mar de taludes cujo manto protector é constituído por enrocamento e que está sujeito a um estado de agitação de características variáveis no tempo. Assim, supondo estacionário o estado de agitação incidente na estrutura entre os instantes $t_{n}$ e $t_{n+1}$, a altura significativa desse estado de agitação, $H_{s}$, assim como o período médio, $T_{m}$, não variam entre esses instantes e o valor médio do dano acumulado no manto num dado instante $t$ pode ser dado por:

$$
\bar{S}(t)=\bar{S}\left(t_{n}\right)+a_{s} N_{s}^{5} T_{m}^{-b}\left(t^{b}-t_{n}^{b}\right), \text { para } t_{n} \leq t \leq t_{n+1} .
$$

em que $\mathrm{N}_{\mathrm{s}}$ é o número de estabilidade definido por $N_{s}=H_{s} / \Delta D_{n 50}$, enquanto $\mathrm{a}_{\mathrm{s}}$ e b são coeficientes empíricos obtidos, por exemplo, em ensaios com modelos físicos reduzidos. A expressão implica que no instante $\mathrm{t}=0$ não existe qualquer dano acumulado no perfil transversal da estrutura, $\bar{S}(0)=0$. Tal significa que a mesma expressão só pode ser aplicada a estruturas que não estejam danificadas ou cuja evolução do dano seja conhecida.

Para evitar a limitação anterior, J. A. MelBy e N. KobaYASHI (1999) reescreveram aquela fórmula resultando

$$
[\bar{S}(t)]^{1 / b}=\left[\bar{S}\left(t_{n}\right)\right]^{1 / b}+\left(a_{s} N_{s}^{5}\right)^{1 / b} \frac{t-t_{n}}{T_{m}}
$$

Aqueles autores indicam que o ajuste óptimo dos valores experimentais aos resultados desta fórmula ocorre para $\mathrm{a}_{\mathrm{s}}=0.011$ e $\mathrm{b}=\mathbf{0 . 5}$. Importa recordar que tais ensaios foram realizados utilizando uma estrutura com manto protector de enrocamento e ondas que rebentavam antes de atingir a estrutura. Ou seja, mais ensaios com modelo físico reduzido têm que ser realizados para obter novos coeficientes para diferentes elementos do manto protector ou outras condições de agitação incidente.

Embora a fórmula de Melby e Kobayashi tenha sido baseada na fórmula apresentada em J. W. VAN DER MEER (1988), ao contrário desta, ela não é uma genuína fórmula de dimensionamento. Trata-se de uma abordagem completamente diferente do problema, pois a fórmula não fornece directamente as dimensões de um elemento do manto. Apenas calculando a evolução do dano do manto protector para a totalidade da vida útil da estrutura é possível utilizar esta fórmula para aquele objectivo. Desta forma, passa a projectar-se a estrutura para resistir não apenas a um único estado de agitação mas a todos os estados de agitação incidentes na estrutura e expectáveis durante a vida útil da mesma.

Não é difícil verificar que mesmo para estados de agitação com pouca energia a eq. (11) prevê um aumento contínuo do dano no manto protector. Se a duração destes estados 
de agitação for muito grande, obtém-se então um valor médio do dano acumulado que não é realista. Impõe-se, por isso, uma correcção a este modelo.

Para reduzir a influência de estados de agitação com pouca energia na simulação do comportamento do manto protector sujeito à agitação marítima estabeleceu-se um patamar para a altura de onda significativa abaixo do qual é impossível o aumento do valor médio do dano acumulado. W. G. SмIтH et al. (1992) propuseram o seguinte valor limite para o número de estabilidade:

$$
\begin{aligned}
& N_{c}=0.4 \frac{6.2 P^{0.18}}{\sqrt{\xi_{m}}}, \text { para } \xi_{m} \leq \xi_{c} . \\
& N_{c}=0.4 \xi_{m}^{P} \frac{\sqrt{\cot \alpha}}{P^{0.13}}, \text { para } \xi_{m}>\xi_{c} .
\end{aligned}
$$

em que $\alpha$ designa o ângulo do talude com o plano horizontal, $\mathrm{P}$ é um parâmetro de permeabilidade do quebra-mar, $\xi_{\mathrm{m}}$ é o número de Iribarren calculado com o período médio, $\mathrm{T}_{\mathrm{m}}$, e o valor crítico desse parâmetro, $\xi_{c}$ é dado por

$$
\xi_{c}=\left[6.2 P^{0.31} \sqrt{\tan \alpha}\right]^{\frac{1}{P+0.5}}
$$

Quando o número de estabilidade do estado de agitação, $\mathrm{N}_{\mathrm{s}}$, está abaixo do valor crítico $\mathrm{N}_{\mathrm{c}}$, assume-se que a estrutura não sofre qualquer incremento no valor médio acumulado do dano. Uma vez que os instantes relevantes para o cálculo do valor médio do dano acumulado estão no fim de cada intervalo de tempo durante o qual se podem assumir constantes as características do estado de agitação, $S_{n+1}$, a eq. (11) pode reescrever-se como

$$
\begin{array}{r}
\bar{S}_{n+1}=\left(\bar{S}_{n}^{1 / b}+\left(a_{s} N_{s}^{5}\right)^{1 / b} \frac{t_{n+1}-t_{n}}{T_{m}}\right)^{b} \text {, para } N_{s}>N_{c} \\
\bar{S}_{n+1}=\bar{S}_{n} \text {, para } \quad N_{s} \leq N_{c} .
\end{array}
$$

Caso de Estudo 1: Verificação da Segurança ao Modo de Falha por Galgamento de uma Estrutura de Protecção Costeira

\section{Localização}

O caso de estudo apresentado nesta secção diz respeito à verificação da segurança de uma protecção marginal de talude localizada na baía de Liverpool (fig. 4). Esta baía situa-se no Reino Unido e está limitada a Este por Merseyside e a Sul pelo Norte de Gales.

A estrutura está virada a Oeste, é impermeável, com um talude exterior uniforme a 1:2 e com uma rugosidade $\mathrm{r}=0.75$. A estrutura desenvolve-se ao longo de $4.5 \mathrm{~km}$, o seu coroamento varia entre $7 \mathrm{~m}$ OD (OD=Ordnance Datum; fig. 5) e $11.5 \mathrm{~m}$ OD e o pé do talude situa-se à cota $0 \mathrm{~m} O D$.

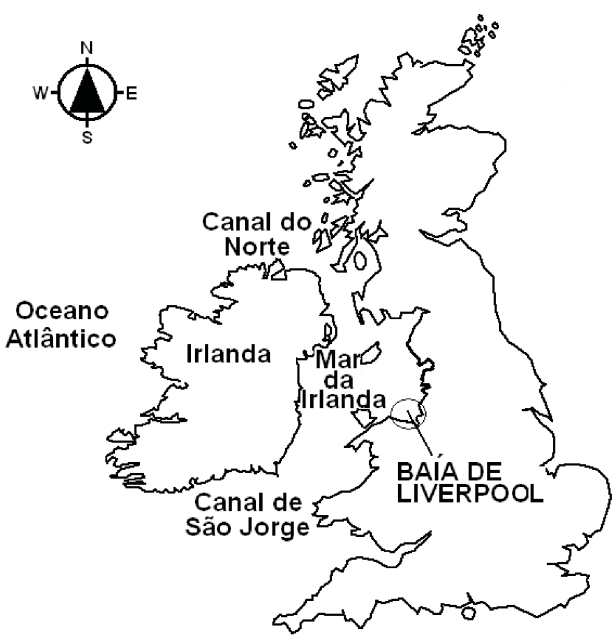

Fig. 4 - Localização do caso de estudo.

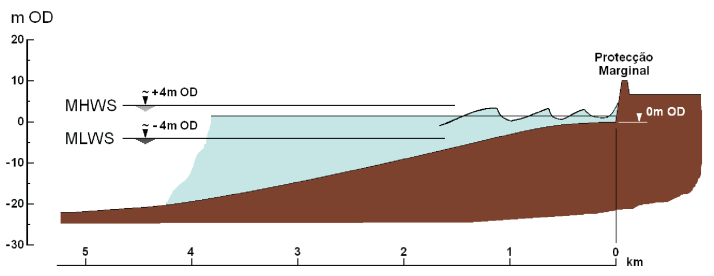

Fig. 5 - Representação esquemática da protecção marginal situada na baía de Liverpool.

\section{Caracterização das variáveis}

A caracterização das variáveis relevantes nas fórmulas de H\&R e de Van der Meer e Janssen é feita seguidamente, à excepção da altura de coroamento, CL, considerada como o parâmetro de dimensionamento. Estabeleceram-se distribuições empíricas para as variáveis para as quais as medições existentes não se prestavam a ser modeladas pelas distribuições pré-definidas, como é o caso dos períodos de pico da ondulação e dos níveis de maré previstos em Liverpool. A função densidade de probabilidade dos níveis de maré, $f(z)$, foi incluída neste artigo para ilustrar este ponto.

É importante referir que, para além da escolha da fórmula de galgamentos, um dos principais factores que contribui para o grau de confiança associado à probabilidade de falha determinada por métodos probabilisticos diz respeito às distribuições estatísticas adoptadas para descrever as variáveis de resistência e de solicitação presentes na fórmula de galgamentos utilizada para descrever falha. Estas distribuições devem ser escolhidas de forma cuidadosa, especialmente quando são poucos os dados disponíveis, o que se verifica na maioria dos casos. A escolha da distribuição não se pode limitar a um puro exercício de ajuste de 
distribuições pré-definidas a medições da variável em causa. Neste sentido, é muito importante uma utilização consciente do grande número de software comercial que se encontra disponível actualmente, tal como o @RISK (PALISADE CORPORATION, 1994, 2002), e que disponibiliza ao utilizador uma vasta gama de distribuições pré-definidas, que facilmente podem ser usadas incorrectamente. É crucial não esquecer o significado físico da variável em questão e como este se reflecte na definição da distribuição estatística. Os métodos probabilísticos de nível II (tal como o método implementado no PARASODE-BALI) permitem o cálculo de factores de sensibilidade que indicam a influência de cada uma das variáveis aleatórias na variabilidade do valor da função de falha, Z, permitindo direccionar esforços e recursos no sentido de obter e trabalhar dados por forma a melhor descrever e caracterizar as variáveis de maior influência.

\section{Caracterização do estado de agitação marítima incidente}

A protecção marginal está exposta à acção de vagas geradas localmente no Mar da Irlanda, mas está protegida pela Irlanda da acção directa de ondulação proveniente do Oceano Atlântico (fig. 4). No entanto, ondulação proveniente do Oceano Atlântico pode atingir a estrutura através do Canal de São Jorge e do Canal do Norte. Consequentemente, estruturas na baía de Liverpool podem estar sujeitas à acção conjunta de vagas e ondulação.

B. A. SALIH (1989) analisou um diagrama de dispersão (fig. 6), retirado de L. Draper e A. Blakey (1969), descrevendo, a longo prazo, as distribuições de alturas de onda e períodos das vagas na zona da barra do Mersey, na baía de Liverpool. Com base nos seus resultados, foram adoptadas duas distribuições de Weibull para $H_{s(w)}$ e $T_{p(w)}$ caracterizadas pelos parâmetros indicados no QUADRo I. Foi ainda adoptado um coeficiente de correlação linear de 0.6 entre $H_{s(w)}$ e $T_{p(w)}$. Note-se que o que L. Draper e A. Blakey (1969) designaram por "calm" (ver fig. 6) corresponde a dados de agitação cujas condições (alturas de onda e períodos) estão no limite de resolução dos instrumentos de medição. Estas condições representam aproximadamente $51 \%$ do regime de agitação na barra do Mersey e os parâmetros apresentados no QuAdRo I referem-se apenas às vagas registadas. Assumindo que não se verifica a ocorrência de galgamento quando não existem vagas (ou seja, a ondulação só por si não causa galgamentos), as probabilidades de falha obtidas usando as distribuições referentes às vagas registadas foram ajustadas para ter em linha de conta as condições designadas por "calm".

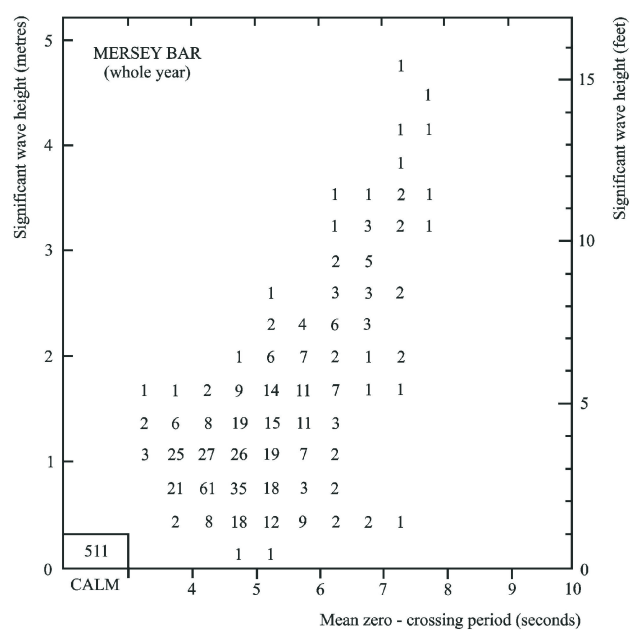

Fig. 6 - Diagrama de dispersão das alturas de onda e períodos das vagas na zona da barra do Mersey (L. Draper e A. Blakey, 1969).

QUADRO I - Parâmetros caracterizadores das distribuições de Weibull para $\mathrm{H}_{\mathrm{s}(\mathrm{w})}$ e $\mathrm{T}_{\mathrm{p}(\mathrm{w})}$ (excluindo as condições designadas por “calm”).

\begin{tabular}{|c|c|c|c|c|c|}
\hline \multicolumn{2}{|c|}{$\mathrm{H}_{\mathrm{s}(\mathrm{w})}(\mathrm{m})$} & \multicolumn{3}{|c|}{$\mathrm{T}_{\mathrm{p}(\mathrm{w})}(\mathrm{s})$} \\
\hline$\mu$ & $\sigma$ & $\begin{array}{c}\text { Limite } \\
\text { Inferior }\end{array}$ & $\mu$ & $\sigma$ & Limite Inferior \\
\hline 1.2 & 0.7 & 0.45 & 6.4 & 1.15 & 4.2 \\
\hline
\end{tabular}

No caso da ondulação, P. J. HAwkEs et al. (1997) apresentam o diagrama de dispersão que descreve, a longo prazo, as distribuições de alturas de onda e períodos na baía de Liverpool. Com base nestes resultados, foi adoptada uma distribuição de Weibull para $\mathrm{H}_{\mathrm{s}(\mathrm{s})}$ com uma média $\mu=0.377 \mathrm{~m}$, um desvio padrão $\sigma=0.332 \mathrm{~m}$ e um limite inferior de $0 \mathrm{~m}$. Para o período de pico do espectro da ondulação, estabeleceu-se uma distribuição empírica com uma média $\mu=13.12 \mathrm{~s}$ e um desvio padrão $\sigma=3.51 \mathrm{~s}$ (fig. 7). Para condições de ondulação, as maiores ondas estão normalmente associadas a menores períodos e um coeficiente de correlação linear de -0.1 foi determinado com base em P. J. HAWKES et al. (1997).

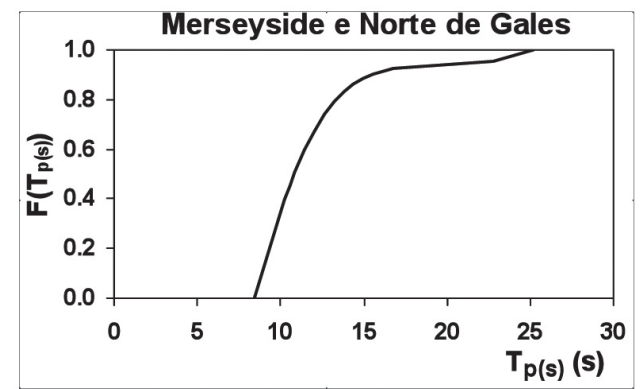

Fig. 7 - Função de distribuição associada aos períodos de pico da ondulação observada/prevista em Merseyside e Norte de Gales. 
No que diz respeito à correlação entre vagas e ondulação, adoptou-se um coeficiente de correlação linear de 0.2 entre $\mathrm{H}_{\mathrm{s}(\mathrm{w})}$ e $\mathrm{H}_{\mathrm{s}(\mathrm{s})}$. P. Hawkes e C. Svensson (2005) sugerem que o valor deste coeficiente pode ser superior para Merseyside e Norte de Gales. No entanto, cálculos semelhantes aos descritos neste caso de estudo mostram que mesmo um valor de 0.4 resulta apenas em diferenças da ordem dos $0.1 \mathrm{~m}$ nas alturas de coroamento necessárias para limitar os galgamentos a valores pré-definidos.

Para verificar o impacto da consideração da ondulação no caso de estudo apresentado, realizaram-se cálculos nos quais apenas foi considerada a actuação de vagas. Verifica-se que, devido às características da ondulação a que a protecção marginal está sujeita na baía de Liverpool, a contribuição desta resulta apenas num aumento da ordem dos $0.1 \mathrm{~m}$ na altura de coroamento. Estas diferenças são da ordem de grandeza das verificadas com os resultados obtidos para os dois valores testados do coeficiente de correlação linear entre $\mathrm{H}_{\mathrm{s}(\mathrm{w})}$ e $\mathrm{H}_{\mathrm{s}(\mathrm{s})}$.

Nos cálculos probabilísticos, não se entrou em linha de conta com a distribuição das direcções da agitação incidente, nem com a correlação entre elas e a altura significativa das vagas e da ondulação, apesar de esta informação, uma vez disponível, ser facilmente incorporada no PARASODE-BALI. Pequenas ondas na baía de Liverpool podem ser provenientes de qualquer direcção, mas não causam galgamentos da protecção marginal. Galgamentos são esperados somente durante os estados de mar mais severos provenientes de Oeste. É a esta direcção, à qual a protecção marginal está directamente exposta, a que estão associados o maior fetch e os ventos mais fortes.

Numa situação real de verificação da segurança, as condições de agitação na barra do Mersey teriam que ser transportadas até à protecção marginal utilizando um modelo não linear de propagação de ondas. Dado que o objectivo deste trabalho é essencialmente o de ilustrar os benefícios da utilização de métodos probabilísticos na verificação da segurança de protecções marginais, foram ignorados o empolamento, a refracção, a interacção ondas-correntes e outros processos que ocorrem na zona costeira. No entanto, para que não se considerassem alturas de onda irrealistas junto à protecção marginal, as distribuições das alturas de onda significativas foram truncadas quando as profundidades junto à estrutura geravam rebentação no talude em frente à protecção marginal (M. T. REIS, 1998).

\section{Caracterização do nível de água}

Neste caso de estudo, fez-se a verificação da segurança da protecção marginal para qualquer nível de água possível. O desempenho da estrutura para valores extremos de nível de água não foi aqui verificado.
PARASODE-BALI permite ao utilizador definir o nível de água como uma variável única ou como a soma de duas componentes: maré astronómica e sobrelevação de origem meteorológica (surge). Para os níveis de maré previstos em Liverpool, estabeleceu-se uma distribuição empírica com uma média $\mu=0.275 \mathrm{~m}$ OD e um desvio padrão $\sigma=2.362 \mathrm{~m}$ OD (fig. 8). Para respresentar a sobrelevação do nível de água, foi adoptada uma distribuição de Gumbel ( $\mu=0.019 \mathrm{~m} ; \sigma=0.192 \mathrm{~m}$ ). As duas componentes do nível de água foram consideradas independentes.

(a)

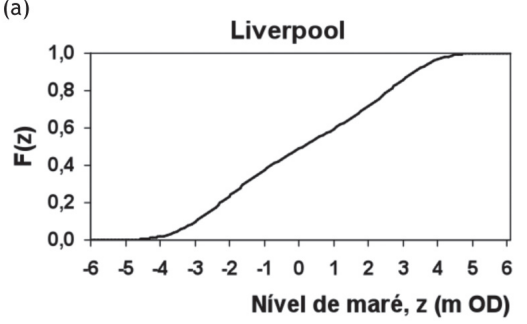

(b)

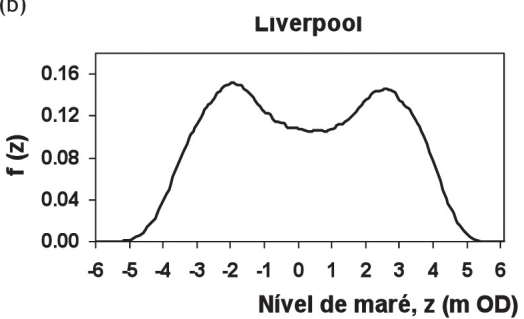

Fig. 8 - Níveis de maré, z, previstos em Liverpool: (a) função de distribuição; e (b) função densidade de probabilidade.

Correlação entre o estado de agitação marítima e o nível de água

Os galgamentos de uma protecção marginal não dependem apenas do estado de agitação marítima ou do nível de água individualmente, mas sim da combinação dos dois factores. Uma tempestade ao largo que poderia eventualmente resultar em alturas de onda elevadas, pode passar despercebida se o nível de água for baixo. Por outro lado, para níveis de água elevados, ondas pequenas poderão causar galgamentos consideráveis. Assim, no dimensionamento de protecções marginais, é a ocorrência simultânea de grandes ondas e de níveis de água elevados que tem particular relevância.

Baseado na informação disponível em P. HAwkEs e C. Svensson (2005) para a área da baía de Liverpool, adoptou-se um coeficiente de correlação de 0.7 entre $\mathrm{H}_{\mathrm{s}(\mathrm{w})}$ e a sobrelevação do nível de água.

Caracterização do ângulo do talude exterior da estrutura

A inclinação que o talude exterior apresenta depois de executado dificilmente é igual ao especificado no projecto. Assim sendo, tan $\alpha$ foi considerado como 
sendo uma variável aleatória normal com média $\mu=0.5$ e desvio padrão igual a $10 \%$ do valor médio (0.05). Obviamente que, admitindo a distribuição normal valores infinitos, esses valores não são compatíveis com a inclinação de um talude. Contudo, a influência das "caudas" da distribuição normal não é significativa quando a um desvio padrão pequeno está associado um valor médio elevado, tal como acontece neste caso.

Caracterização da rugosidade do talude exterior da estrutura

Os valores típicos do parâmetro $r$, que procura reflectir a influência da rugosidade no espraiamento, variam aproximadamente entre 0.5 e 1 , dependendo do tipo de talude (CIRIA/CUR, 1991; P. BESLEY, 1999; J. W. VAN DER Meer, 2002; T. S. Hedges e M. T. ReIs, 2004). Neste caso de estudo, a rugosidade do talude foi considerada como sendo uma variável aleatória caracterizada por uma distribuição Beta, com uma média $\mu=0.75$, um desvio padrão $\sigma=0.008$ e limites inferior e superior de 0.7 e 0.8 , respectivamente. 0 uso desta distribuição contempla o facto de $r$ não poder ser superior à unidade e de ter uma gama específica de valores para o tipo de talude considerado.

\section{Caracterização dos parâmetros das fórmulas}

Seguindo as recomendações de M. T. REIS (1998), os coeficientes $A$ e $B$ na fórmula $H \& R$ foram considerados determinísticos para $\left(R_{\max }\right)_{37 \%, 100}$, i.e. $A=0.00753$ e $B=4.17$, e o parâmetro $e_{B}$ foi considerado como sendo uma variável normal logarítmica, com uma média $\mu=1.049$ e um desvio padrão $\sigma=0.241$.

Seguindo as recomendações de J. W. VAN DeR MEer e J. P. F. M. JANSSEn (1995), os coeficientes A e B da sua fórmula foram considerados como variáveis aleatórias normais, com os seguintes valores para as médias e os devios padrões: i) A: $\mu=5.2, \sigma=0.55$; e ii) $\mathrm{B}: \mu=2.6$, $\sigma=0.35$.

\section{Análise dos resultados}

$\mathrm{Na}$ fig. 9 apresenta-se a comparação dos resultados obtidos através das fórmulas de galgamentos de Hedges e Reis (curvas a traço contínuo) e de Van der Meer e Janssen (curvas a traço interrompido). Esta figura mostra a probabilidade de falha anual, $P_{f}$, em função da altura de coroamento, $\mathrm{CL}$, para diferentes valores do caudal médio admissível, $\mathrm{Q}$.

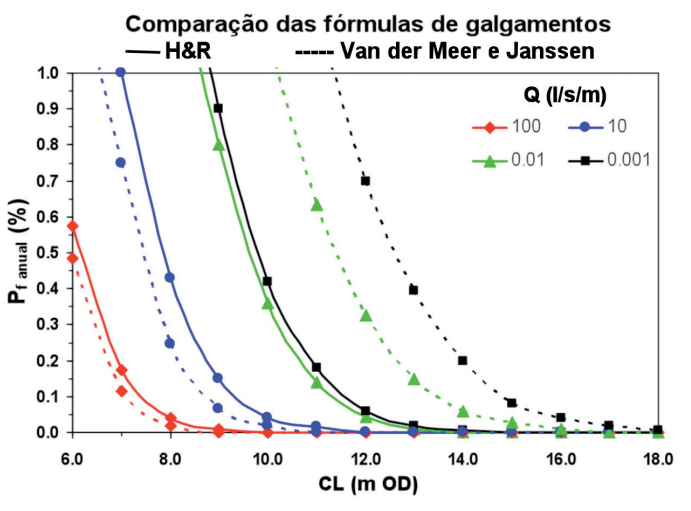

Fig. 9 - Probabilidade de falha anual, $\mathrm{P}_{f}$, versus altura de coroamento, CL, para diferentes valores do caudal médio admissível, $\mathrm{Q}$.

Tal como seria de esperar, a fig. 9 mostra que:

- para qualquer valor de caudal admissível, Q, a probabilidade de falha anual, $\mathrm{P}_{\mathrm{f}}$, diminui à medida que a altura de coroamento, $\mathrm{CL}$, aumenta;

- para o mesmo valor da altura de coroamento, CL, a probabilidade de falha anual, $\mathrm{P}_{\mathrm{f}}$, diminui à medida que o caudal admissível, Q, aumenta.

Dentro das limitações do presente estudo, na fig. 9 pode ver-se também que:

- se os galgamentos tiverem que ser restringidos a valores de $\mathrm{Q}$ relacionados com requisitos de segurança funcional, i.e. $0.001 \leq \mathrm{Q} \leq 0.03 \mathrm{l} / \mathrm{s} / \mathrm{m}$ (ver fig. 3), a fórmula de Van der Meer e Janssen conduz a probabilidades de falha muito superiores às obtidas pela fórmula H\&R; por exemplo, para $\mathrm{Q}=0.01 \mathrm{l} / \mathrm{s} / \mathrm{m}$, a fórmula de Van der Meer e Janssen prevê um valor de $P_{f}$ de $0.64 \%$ para um valor de $C L=11 \mathrm{~m} \mathrm{OD}$, enquanto a fórmula $H \& R$ prevê um valor de $P_{f}$ de $0.14 \%$ (4.5 vezes inferior); ou em termos de dimensionamento, para $\mathrm{Q}=0.01 \mathrm{l} / \mathrm{s} / \mathrm{m}$, a fórmula de Van der Meer e Janssen sugere um valor necessário de $\mathrm{CL}$ de $11.4 \mathrm{~m}$ OD para um valor de $P_{f}=0.5 \%$, enquanto a fórmula $H \& R$ prevê um valor de CL de 9.6m OD;

- para valores relacionados com requisitos de segurança estrutural, i.e. $2 \leq \mathrm{Q} \leq 200 \mathrm{l} / \mathrm{s} / \mathrm{m}$ (ver fig. 3), a fórmula H\&R é um pouco mais conservativa que a fórmula de Van der Meer e Janssen; por exemplo, para $Q=10 \mathrm{l} / \mathrm{s} / \mathrm{m}$, a fórmula de Van der Meer e Janssen prevê um valor de $P_{f}$ de $0.25 \%$ para um valor de $C L=8 \mathrm{~m} \mathrm{OD}$, enquanto a fórmula H\&R prevê um valor de $P_{f}$ de $0.43 \%$ (1.8 vezes superior); ou em termos de dimensionamento, para $\mathrm{Q}=10 \mathrm{l} / \mathrm{s} / \mathrm{m}$, uma altura de coroamento de $7.3 \mathrm{~m}$ OD seria necessária para um valor de $\mathrm{P}_{\mathrm{f}}=0.5 \%$ segundo a fórmula de Van der Meer e Janssen, enquanto a fórmula H\&R propõe uma altura de coroamento de $7.8 \mathrm{~m}$ OD. 
A fig. 9 também mostra que, para valores de $P_{f \text { anual }}>0.1 \%$, um pequeno aumento no valor de $\mathrm{CL}$ resulta numa diminuição substancial de $P_{f}$, enquanto para menores valores de $P_{f}$, uma redução significativa de $P_{f}$ necessita de um maior incremento de CL.

Por fim, tendo em conta que as probabilidades de falha anuais consideradas admissíveis no âmbito deste caso de estudo são inferiores ou iguais a $1 \%$, é possível estabelecer com base na fig. 9 quais a secções transversais da estrutura de protecção marginal (com valores de altura de coroamento, $\mathrm{CL}$, que variam entre $7 m$ OD e $11.5 m$ OD) que se encontram em segurança no que diz respeito ao galgamento, para os vários valores de caudais admissíveis, $\mathrm{Q}$, considerados.

Caso de Estudo 2: Verificação da Segurança ao Modo de Falha por Instabilidade Hidráulica do Manto Protector de um Quebra-mar de Taludes

Uma vez que as fórmulas para a evolução do dano foram estabelecidas a partir de resultados de ensaios de estruturas com mantos de enrocamento, o teste que aqui se apresenta diz respeito a um quebra-mar de taludes com manto de enrocamento: o quebra-mar do porto de pesca de Sines (I. A. SousA, 2007).

Neste caso, os elementos do manto, cujo peso médio é $45 \mathrm{kN}$, foram colocados aleatoriamente em duas camadas num talude com um declive de $1: 2$. Assumindo que o peso volúmico da rocha utilizada é $29 \mathrm{kN} / \mathrm{m}^{3}$, o diâmetro nominal mediano dos elementos do manto é $D_{n 50}=1.16 \mathrm{~m}$. A profundidade no pé do talude é suficiente para evitar a rebentação das ondas antes destas atingirem o manto.

\section{Transferência dos parâmetros da agitação marítima}

O molhe do porto de pesca está localizado na zona actualmente protegida pelo molhe oeste do porto de Sines. Tal implica que a transferência das características da agitação marítima medida na bóia direccional SINES 1D até à zona do molhe do porto de pesca tenha que ser levada a cabo por um modelo numérico capaz de simular a difracção induzida pelo molhe oeste do porto de Sines, para além da refracção induzida pela variação da profundidade ao longo da propagação da agitação marítima. Para tal utilizou-se o modelo numérico DREAMS (C.J.E.M. ForTES, 2002). Este modelo calcula a propagação e deformação de ondas marítimas monocromáticas em regiões costeiras. Baseia-se na forma elíptica da equação do declive suave que descreve os efeitos combinados de refracção e difracção de ondas monocromáticas que se propagam sobre fundos de declive suave como são os que ocorrem em portos, bacias abrigadas e zonas costeiras.
Após uma breve análise das características da agitação marítima medida na bóia-ondógrafo SINES 1D e da variação da profundidade na região em estudo, decidiu-se propagar ondas com direcções entre $190^{\circ}$ e $330^{\circ}$ (com um intervalo de $10^{\circ}$ ) e períodos entre $5.5 \mathrm{~s}$ e $15.5 \mathrm{~s}$ (com um intervalo de 1s). Tal implica que 165 ondas diferentes foram propagadas.

O domínio computacional foi discretizado com duas malhas (fig. 10): malha\#1 para períodos entre 5.5s e 8.5s, com 158102 nós e 313430 elementos triangulares; malha\#2 para períodos entre $9.5 \mathrm{~s}$ e 15.5s, com 115431 nós e 228372 elementos triangulares. Considerou-se o valor médio anual do nível de maré: $+2.0 \mathrm{~m}(\mathrm{ZH})$.

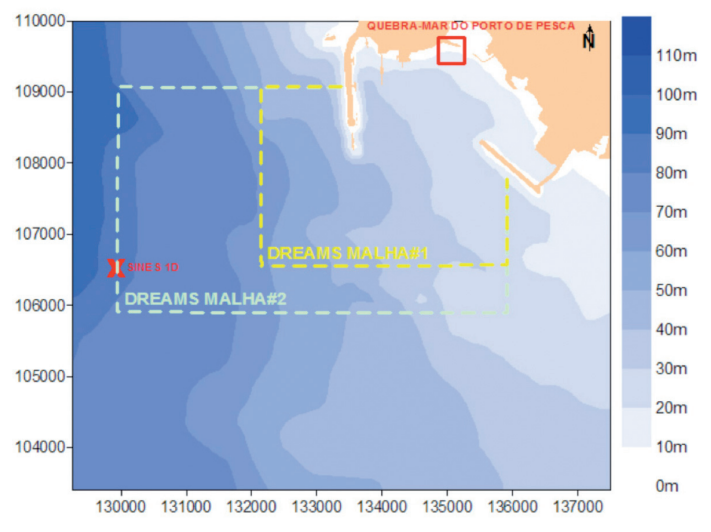

Fig. 10 - Domínio em estudo e malhas de cálculo.

Para cada direcção de onda, determinaram-se os valores dos coeficientes de altura de onda, as direcções de onda e as cristas das ondas em todos os nós de cálculo, bem como as alturas e as direcções das ondas em pontos seleccionados próximo do porto de pesca (QuAdros II e III).

Da análise desses quadros é evidente que apenas as ondas provenientes de Sul $\left(190^{\circ}\right.$ a $\left.220^{\circ}\right)$, especialmente as de grande período que são amplificadas, atingem o molhe do porto de pesca sem perder a maior parte da sua energia.

Uma vez conhecidos os coeficientes de altura de onda é possível transferir as características da agitação marítima medida na bóia SINES 1D para a zona em frente ao molhe do porto de pesca de Sines. As características da agitação marítima medida ao longo de cerca de 14.5 anos foram transferidas. A maior altura de onda obtida frente ao molhe do porto de pesca foi $3.53 \mathrm{~m}$. Tal como esperado, esta altura de onda é muito menor do que as profundidades na zona de implantação do molhe o que implica a inexistência de rebentação da onda nessa zona. 
QUADRo II - Coeficientes de altura de onda na zona do molhe para direcções da agitação marítima entre $190^{\circ}$ e $250^{\circ}$ (na bóia SINES 1D).

\begin{tabular}{cccccccc}
\hline \multicolumn{7}{c}{ Direcção $\left({ }^{\circ}\right)$} \\
\cline { 2 - 8 } (s) & 190 & 200 & 210 & 220 & 230 & 240 & 250 \\
\hline 5.5 & 0.76 & 0.89 & 0.86 & 0.23 & 0.59 & 0.17 & 0.25 \\
6.5 & 0.85 & 0.90 & 0.87 & 0.41 & 0.53 & 0.17 & 0.20 \\
7.5 & 0.88 & 0.90 & 0.89 & 0.65 & 0.43 & 0.34 & 0.25 \\
8.5 & 0.88 & 0.91 & 0.91 & 0.74 & 0.38 & 0.35 & 0.09 \\
9.5 & 0.78 & 0.71 & 0.84 & 0.74 & 0.19 & 0.33 & 0.19 \\
10.5 & 0.91 & 0.71 & 0.87 & 0.73 & 0.17 & 0.34 & 0.26 \\
11.5 & 1.00 & 0.82 & 0.95 & 0.66 & 0.13 & 0.38 & 0.30 \\
12.5 & 1.02 & 0.85 & 1.05 & 0.59 & 0.17 & 0.41 & 0.40 \\
13.5 & 1.02 & 1.02 & 1.13 & 0.51 & 0.21 & 0.46 & 0.47 \\
14.5 & 1.00 & 1.22 & 1.17 & 0.35 & 0.24 & 0.45 & 0.51 \\
15.5 & 0.92 & 1.33 & 1.12 & 0.22 & 0.33 & 0.46 & 0.52 \\
\hline
\end{tabular}

QUADRO III - Coeficientes de altura de onda na zona do molhe para direcções da agitação marítima entre $260^{\circ}$ e $330^{\circ}$ (na bóia SINES 1D).

\begin{tabular}{ccccccccc}
\hline$T$ & \multicolumn{7}{c}{ Direcção $\left(^{\circ}\right)$} \\
\cline { 2 - 9 }$(\mathrm{s})$ & 260 & 270 & 280 & 290 & 300 & 310 & 320 & 330 \\
\hline 5.5 & 0.20 & 0.14 & 0.09 & 0.05 & 0.07 & 0.06 & 0.04 & 0.02 \\
6.5 & 0.16 & 0.17 & 0.16 & 0.12 & 0.04 & 0.05 & 0.08 & 0.03 \\
7.5 & 0.17 & 0.14 & 0.22 & 0.10 & 0.14 & 0.07 & 0.10 & 0.03 \\
8.5 & 0.24 & 0.17 & 0.18 & 0.13 & 0.17 & 0.08 & 0.12 & 0.11 \\
9.5 & 0.19 & 0.23 & 0.12 & 0.24 & 0.11 & 0.10 & 0.15 & 0.12 \\
10.5 & 0.08 & 0.25 & 0.23 & 0.16 & 0.21 & 0.16 & 0.08 & 0.06 \\
11.5 & 0.11 & 0.15 & 0.31 & 0.19 & 0.17 & 0.17 & 0.19 & 0.13 \\
12.5 & 0.21 & 0.06 & 0.28 & 0.26 & 0.16 & 0.08 & 0.14 & 0.16 \\
13.5 & 0.28 & 0.11 & 0.25 & 0.29 & 0.22 & 0.15 & 0.09 & 0.09 \\
14.5 & 0.34 & 0.18 & 0.14 & 0.27 & 0.24 & 0.20 & 0.16 & 0.09 \\
15.5 & 0.39 & 0.19 & 0.12 & 0.26 & 0.25 & 0.21 & 0.21 & 0.12 \\
\hline
\end{tabular}

Geração da série temporal dos parâmetros dos estados de agitação

A maior parte do dano no manto protector será causada por estados de agitação com valores grandes da altura de onda. Por outro lado, a ocorrência de tais estados de agitação é verdadeiramente excepcional. Por isso, a probabilidade de ocorrência dos mesmos não será correctamente obtida a partir da distribuição estatística ajustada à totalidade do clima de agitação. Além disso, e tal como referido anteriormente, é necessário reduzir a influência dos estados de agitação de baixa energia na simulação do comportamento do manto sob a acção da agitação marítima.

Para levar em conta os condicionantes anteriores no processo de simulação, apenas os valores tri-horários transferidos para o local de implantação do molhe do porto de pesca para os quais o número de estabilidade, $\mathrm{N}_{\mathrm{s}}$, exceda o valor crítico, $\mathrm{N}_{\mathrm{c}}$, foram utilizados na definição das distribuições de $H_{s}$ e de $T_{m}$. Verificou-se que o número de estabilidade crítico estava contido num intervalo muito estreito (entre 1.09 e 1.39) e, por isso, talvez seja possível substituí-lo por um limiar fixo. De acordo com o critério do número de estabilidade crítico, apenas em $0.061 \%$ do tempo é que o molhe do porto de pesca está sujeito a estados de agitação potencialmente prejudiciais para o mesmo.

Utilizando os testes de chi-quadrado, de Anderson-Darling e de Kolmogorov-Smirnov verificou-se o ajuste de várias distribuições aos valores de $H_{s}$ e de $T_{m}$. Face aos resultados obtidos optou-se por modelar $H_{s}$ com uma distribuição de Gumbel caracterizada por um parâmetro de localização $\mathrm{a}=2.97 \mathrm{~m}$ e por um parâmetro de escala $b=0.17 m$, enquanto $T_{m}$ foi modelado por uma distribuição logística com um parâmetro de localização $\alpha=8.35 \mathrm{~s}$ e com um parâmetro de escala $\beta=0.51 \mathrm{~s}$.

O pacote de software @RISK foi utilizado para gerar as séries temporais dos parâmetros dos estados de agitação frente ao local de implantação do molhe do porto de pesca. Utilizou-se a técnica de amostragem Latin Hypercube Sampling. Estas séries temporais podem ser geradas desprezando a eventual dependência entre valores consecutivos que pode observar-se em registos de agitação marítima porque o valor médio do dano acumulado obtido com as eqs. (15) e (16) não depende da sequência de ondas incidentes na estrutura.

\section{Resultados}

Foram realizadas 100 simulações, cada uma relativa a um intervalo de tempo com a duração de 100 anos. Tal implicou a produção de 21219400 amostras de cada uma das variáveis consideradas aleatórias $\left(H_{s}\right.$ e $\left.T_{m}\right)$. As eqs. (15) e (16) foram utilizadas, depois da geração de cada amostra de $H_{s}$ e $T_{m}$ para avaliar a evolução do valor médio do dano no manto protector. A fig. 11 apresenta a evolução do dano em 5 das 100 simulações realizadas, bem como a curva obtida da média dessas 100 simulações.

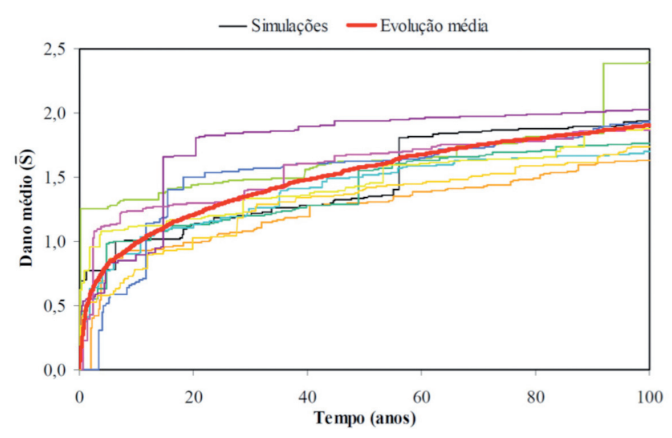

Fig. 11 - Evolução do valor médio do dano acumulado em cinco simulações com 100 anos de duração e na média das 100 simulações realizadas com um manto protector de enrocamento com $45 \mathrm{kN}$. 
A fig. 11 mostra que os incrementos no dano ocorrem em eventos discretos. Importa referir que a maior parte do dano é o resultado de ocorrências extraordinárias. Também pode observar-se nessa figura, especialmente na curva com a média das 100 simulações, que existe uma tendência para o abrandamento do dano acumulado à medida que o manto vai ficando danificado. Tal pode interpretar-se como a aproximação a um estado de equilíbrio que nunca é alcançado.

Em nenhuma das simulações realizadas ocorreu a ruína da estrutura, com base no limiar de dano definido por J. W. VAN DER MEER (1988) - $\overline{\mathrm{S}}>8$. Importa referir que tal resultado não implica que seja nula a probabilidade de falha do manto protector. Quando a probabilidade de falha é muito pequena deve aumentar-se o número de simulações. Uma vez que o objectivo do trabalho não era a avaliação da probabilidade de falha, o número de simulações não foi aumentado. Contudo, este exercício mostrou que deve ser pequena a probabilidade de falha do manto protector do molhe do porto de pesca de Sines.

Para se ganhar sensibilidade à influência da dimensão dos elementos no desempenho do manto, bem como no procedimento de simulação propriamente dito, decidiu-se repetir as simulações com elementos do manto mais leves (peso médio de $22.5 \mathrm{kN}$ e $D_{n 50}=0.92 \mathrm{~m}$ ). A fig. 12 , que é semelhante à fig. 11, sumariza os resultados obtidos. Uma vez que os elementos do manto são mais pequenos espera-se que mais estados de agitação sejam incluídos na simulação. Com efeito, alguns dos estados de agitação que não foram considerados anteriormente por não ser expectável que causassem dano ao manto existente $(45 \mathrm{kN})$, poderão causar dano ao novo manto protector. Por isso, foi necessário reanalisar os parâmetros dos estados de agitação transferidos para a zona de implantação do molhe do porto de pesca, como indicado mais atrás.

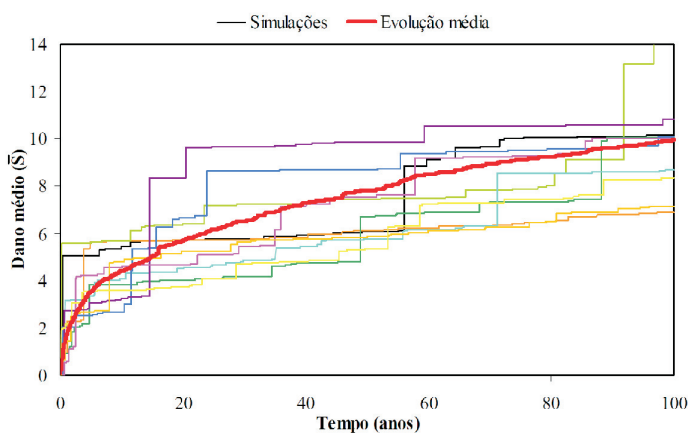

Fig. 12 - Evolução do valor médio do dano acumulado em cinco simulações com 100 anos de duração e na média das 100 simulações realizadas com um manto protector de enrocamento com $22.5 \mathrm{kN}$.

Atendendo ao critério do número de estabilidade crítico, agora em $0.134 \%$ do tempo o molhe estará sujeito a estados de agitação capazes de causar dano. $H_{s}$ foi modelado utilizando uma distribuição de Pearson do tipo V, com um desvio para a direita de $0.19 \mathrm{~m}$ e caracterizado por um parâmetro de forma $\alpha=32.46$ e um parâmetro de escala $\beta=77.36 \mathrm{~m}$. $T_{m}$ foi modelado utilizando a distribuição logística com parâmetro de localização $\alpha=8.01 \mathrm{~s}$ e parâmetro de escala $\beta=0.51 \mathrm{~s}$.

Os resultados mostram que se o manto protector do molhe do porto de pesca de Sines fosse constituído por enrocamento com um peso médio de $22.5 \mathrm{kN}$ a sua probabilidade de falha ao longo de 100 anos seria 78\%. Avaliou-se também a probabilidade de falha para intervalos de tempo mais curtos: $\quad P_{f}^{50}=35 \%, P_{f}^{25}=20 \%$ e $P_{f}^{10}=4 \%$. Mais uma vez assumiu-se que o manto falha quando $\overline{\mathrm{S}}>8$, tal como proposto em J. W. VAN DER MeER (1988). Importa referir que J. A. MelBy (1999) declara que em alguns dos ensaios em modelo físico que levaram às fórmulas e coeficientes da eq. (11), valores do dano médio de 12 foram observados sem que tal implicasse a ruína do manto protector (i.e. exposição do filtro).

Tendo em atenção o objectivo de obter mais informação sobre a influência do critério escolhido para remover estados de agitação de baixa energia na simulação do comportamento do manto protector - o número de estabilidade crítico - variou-se o valor deste número de estabilidade crítico. Primeiro aumentou-se em $10 \%$ o seu valor resultando as equações

$$
\begin{aligned}
& N_{c}=0.44 \frac{6.2 P^{0.18}}{\sqrt{\xi_{m}}}, \text { para } \xi_{m} \leq \xi_{c} \\
& N_{c}=0.44 \xi_{m}^{P} \frac{\sqrt{\cot \alpha}}{P^{0.13}}, \text { para } \xi_{m}>\xi_{c}
\end{aligned}
$$

Após uma nova análise dos parâmetros de agitação transferidos, verificou-se que, de acordo com o novo critério para o número de estabilidade crítico enunciado nas eqs. (17) e (18) apenas durante $0.101 \%$ do tempo o molhe do porto de pesca está exposto a estados de agitação potencialmente perigosos. Nas simulações com a duração de 100 anos realizadas, $H_{s}$ foi modelado como uma distribuição normal cuja média é $2.82 \mathrm{~m}$ e cujo desvio padrão é $0.37 \mathrm{~m}$. Também $\mathrm{T}_{\mathrm{m}}$ foi modelado como uma distribuição normal com média de $8.16 \mathrm{~s}$ e desvio padrão de $0.91 \mathrm{~s}$.

Depois de realizada uma centena de simulações com a duração de 100 anos cada, nunca se observou a ruína do manto protector. Assim, de acordo com o critério do número de estabilidade crítico aumentado pode afirmarse que a probabilidade de falha é $0 \%$.

Reduzindo em $10 \%$ o valor do número de estabilidade crítico, obteve-se

$$
\begin{aligned}
& N_{c}=0.36 \frac{6.2 P^{0.18}}{\sqrt{\xi_{m}}}, \text { para } \xi_{m} \leq \xi_{c} . \\
& N_{c}=0.36 \xi_{m}^{P} \frac{\sqrt{\cot \alpha}}{P^{0.13}}, \text { para } \xi_{m}>\xi_{c} .
\end{aligned}
$$


Atendendo a este valor reduzido do número de estabilidade crítico verifica-se que durante $0.235 \%$ do tempo o molhe do porto de pesca está sujeito a estados de agitação capazes de o danificar. Desta vez $\mathrm{H}_{\mathrm{s}}$ foi modelado utilizando uma distribuição de Pearson tipo $\mathrm{V}$, desviada para a direita de $1.46 \mathrm{~m}$ e caracterizada por um parâmetro de forma $\alpha=3.34$ e por um parâmetro de escala $\beta=2.12 \mathrm{~m}$, enquanto $\mathrm{T}_{\mathrm{m}}$ foi modelado utilizando uma distribuição de Wald com um desvio para a direita de $0.2 \mathrm{~s}$ e com um parâmetro de localização $\mu=7.54 \mathrm{~s}$ e um parâmetro de escala $\lambda=548.15 \mathrm{~s}$. Utilizando este número de estabilidade crítico reduzido atingiu-se a ruína em todas as simulações, $P_{f}=100 \%$.

Foi ainda realizado um último teste que consistiu em substituir o número de estabilidade crítico por um patamar na altura significativa do estado de agitação incidente na estrutura. Para determinar o valor daquele patamar utilizou-se a fórmula de Hudson e as recomendações do Shore Protection Manual (1984) para o projecto de mantos protectores de enrocamento. Se um manto protector com enrocamento de peso mediano igual a $22.5 \mathrm{kN}$ fosse projectado seguindo aquelas recomendações, o estado de agitação de projecto teria uma altura significativa $\mathrm{H}_{\mathrm{s}}=2.73 \mathrm{~m}$ e $H_{1 / 10}=3.47 \mathrm{~m}$.

Analisando mais uma vez os parâmetros dos estados de agitação transferidos, verificou-se que em $0.061 \%$ do tempo $\mathrm{H}_{\mathrm{s}}>2.73 \mathrm{~m}$. Tal implica que este novo critério de limitação da influência de estados de agitação de energia baixa na resposta do manto protector é mais restritivo do que o anterior. Logo a probabilidade de falha obtida com este novo patamar deve ser inferior à anterior.

Nas simulações cujos resultados se apresentam na fig. 13, $\mathrm{H}_{\mathrm{s}}$ foi modelado com uma distribuição de Weibull desviada para a direita de $2.73 \mathrm{~m}$ e caracterizada por um parâmetro de forma $\alpha=1.52 \mathrm{~m}$ e um parâmetro de escala $\beta=0.37 \mathrm{~m}$. $\mathrm{T}_{\mathrm{m}}$ foi modelado utilizando uma distribuição normal com média de $8.34 \mathrm{~s}$ e desvio padrão de 0.90 s. Apenas em 3 das 100 simulações de 100 anos foi atingida a ruína do manto protector. Mais uma vez pode observar-se na figura que $o$ incremento do valor médio do dano ocorre em episódios de duração muito limitada, sendo notável que a maior parte do dano está associado a episódios extraordinários.

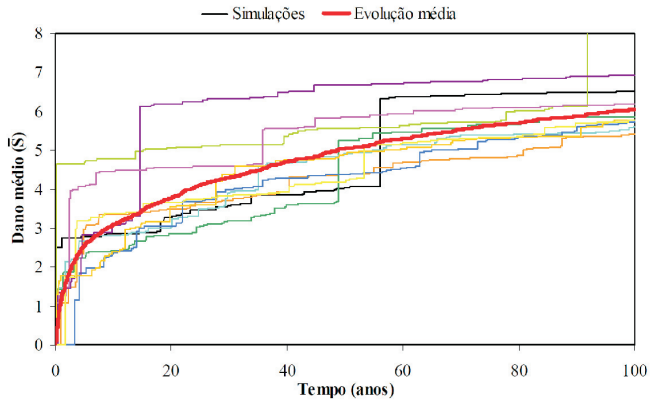

Fig. 13 - Evolução do valor médio do dano acumulado em cinco simulações com 100 anos de duração e na média das 100 simulações realizadas com um manto protector de enrocamento com $22.5 \mathrm{kN}$ e utilizando um patamar de $2.73 \mathrm{~m}$ para a altura significativa da agitação marítima incidente no manto do quebra-mar.
Foram também realizadas simulações com uma duração de cinco anos, fig. 14. Este tipo de aplicação do procedimento já descrito será de grande utilidade na programação das obras de manutenção / reparação do manto protector destas estruturas.

Simulou-se a evolução do dano médio de um manto protector constituído por enrocamento com $22.5 \mathrm{kN}$ de peso mediano utilizando o número de estabilidade crítico definido por W. G. SMITH et al. (1992), sendo $H_{s}$ modelado com uma distribuição de Pearson $V$ desviada para a direita de $0.19 \mathrm{~m}$, caracterizada por um parâmetro de forma $\alpha=32.46$ e um parâmetro de escala $\beta=77.36 \mathrm{~m}$ e $T_{m}$ modelado com uma distribuição logística em que o parâmetro de localização é $\alpha=8.01 \mathrm{~s}$ e o parâmetro de escala é $\beta=0.51 \mathrm{~s}$. Em apenas 3 das 100 simulações o valor médio do dano acumulado excedeu o valor 8 , isto é, o manto atingiu a ruína, logo $P_{f}=3 \%$. Os resultados apresentados na fig. 14 dizem respeito a estas simulações em que o dano inicial do manto era $\overline{\mathrm{S}}_{\mathrm{n}}=6$. Tratando-se de um período mais curto, torna-se mais evidente que as variações no valor médio do dano acumulado estão associadas a um número muito limitado de episódios com ondas muito grandes.

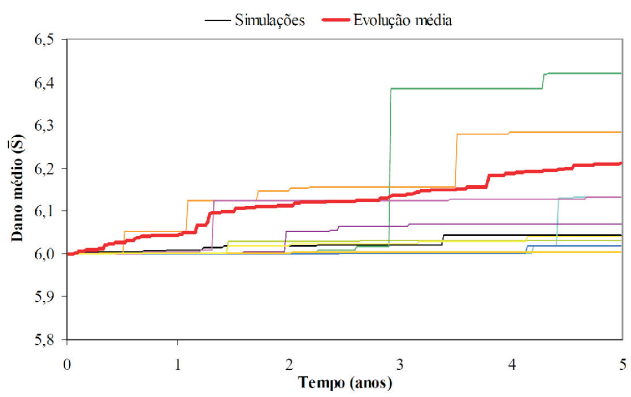

Fig. 14 - Evolução do valor médio do dano acumulado em cinco simulações com 5 anos de duração e na média das 100 simulacões realizadas com um manto protector de enrocamento com $22.5 \mathrm{kN}$ previamente danificado.

Simularam-se também outros valores do valor médio do dano inicial, $\bar{S}_{n}=3.0$ até $\bar{S}_{n}=7.5$. A fig. 15 resume as probabilidades de ruína obtidas. De referir que sendo sempre 100 o número de simulações realizadas, independentemente da duração da simulação, a resolução da probabilidade de ruína foi de $1 \%$.

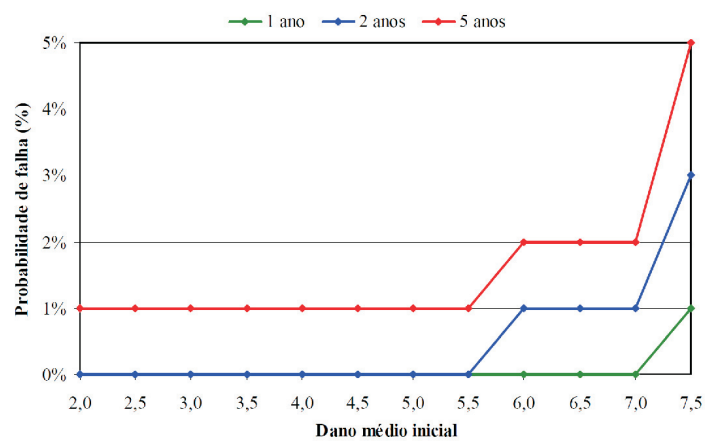

Fig. 15 - Probabilidade de falha para diversas durações das simulações de manto protector de enrocamento com $22.5 \mathrm{kN}$ e valor médio do dano inicial acumulado. 


\section{Considerações Finais}

Neste artigo, ilustra-se o trabalho que o Núcleo de Portos e Estruturas Marítimas do Laboratório Nacional de Engenharia Civil (LNEC) tem vindo a desenvolver no âmbito da verificação da segurança à estabilidade e ao galgamento de estruturas marítimas utilizando métodos probabilísticos de níveis II e III. Apresentam-se dois casos de estudo: 1) verificação da segurança ao modo de falha por galgamento de uma estrutura de protecção marginal localizada na baía de Liverpool, Reino Unido; e 2) verificação da segurança ao modo de falha por instabilidade hidráulica do manto protector de um quebra-mar de taludes.

Para o primeiro caso de estudo, o artigo ilustra os diferentes resultados obtidos com duas fórmulas de galgamentos distintas para o cálculo da probabilidade de falha da estrutura para diversos valores do caudal médio admissível de galgamentos. Para os caudais mais elevados, associados a requisitos de segurança estrutural, as fórmulas prevêem probabilidades de falha semelhantes. No entanto, as diferenças são maiores para os caudais mais pequenos, usualmente relacionados com requisitos de segurança funcional em áreas urbanas. Neste caso, a utilização de uma das fórmulas resultaria em estruturas que implicariam maiores investimentos e maior impacto ambiental na zona envolvente. Estes resultados salientam o facto da escolha da fórmula de galgamentos a utilizar nos cálculos probabilísticos ser muito importante, uma vez que a utilização de diferentes fórmulas pode conduzir a resultados muito díspares.

Para o segundo caso de estudo, apresentaram-se os resultados do estudo da evolução do dano no quebra-mar do porto de pesca de Sines. Como este quebra-mar foi construído antes da conclusão do molhe Oeste de Sines, os elementos utilizados no seu manto protector têm um peso muito superior ao necessário actualmente para resistir à acção das ondas nele incidentes. Por essa razão, e para ganhar sensibilidade ao procedimento de simulação, estudou-se também a evolução do dano de um quebra-mar colocado na mesma posição mas cujos elementos do manto protector tinham um peso igual a metade do peso dos elementos utilizados no quebra-mar do porto de pesca. Avaliou-se também a sensibilidade dos resultados ao valor do número de estabilidade crítico utilizado para remoção da simulação de estados de agitação de energia baixa. Verificou-se que os resultados variam drasticamente para uma variação de apenas $10 \%$ daquele valor o que implica a necessidade de definição cuidadosa do mesmo.

Apesar de não estar ilustrado neste artigo, importa também realçar que a qualidade dos resultados obtidos depende não só da fidelidade com que as funções de falha utilizadas retratam a realidade, mas também da fiabilidade das distribuições estatísticas adoptadas para descrever as variáveis presentes nestas funções e consequentemente da veracidade dos dados utilizados. Quando os dados recolhidos e a que se tem acesso não são em quantidade e qualidade suficiente para representar, por exemplo, as condições de agitação marítima num período alargado, não é possível aproveitar em pleno as vantagens dos cálculos probabilísticos.

Por fim, os resultados obtidos ilustram ainda a utilidade dos cálculos probabilísticos na verificação da segurança de estruturas marítimas: no cálculo determinístico, para um determinado valor do parâmetro de dimensionamento (a altura de coroamento de uma protecção marginal ou o diâmetro nominal dos elementos do manto de um quebra-mar) determina-se apenas se a estrutura falha ou não; no cálculo probabilístico, a probabilidade da estrutura falhar para o valor do parâmetro de dimensionamento considerado é também determinada. Esta informação adicional faz com que os cálculos probabilísticos sejam muito úteis na decisão de se a estrutura pode ou não ser considerada segura e, no caso de não ser, qual o incremento do parâmetro de dimensionamento necessário para minimizar os impactos económicos e ambientais, garantindo simultaneamente os requisitos de segurança funcional e estrutural.

\section{Referências Bibliográficas}

Beaumont, G.P. (1986) - Probability and Random Variables. Ellis Horwood Ltd, Chichester, Reino Unido;

Besley, P. (1999) - Overtopping of Seawalls: Design and Assessment Manual. R\&D Technical Report W178, Environment Agency, Bristol, Reino Unido;

CIRIA (1984) - Rationalization of Safety and Serviceability Factors in Structural Codes. Relatório $N^{\circ}$ 63, CIRIA, Londres;

CIRIA/CUR (1991) - Manual on the Use of Rock in Coastal and Shoreline Engineering. Publicação Especial $N^{\circ} 83$, CIRIA, Londres;

CIRIA, CUR, CETMEF (2007) - The Rock Manual. The Use of Rock in Hydraulic Engineering. Publicação

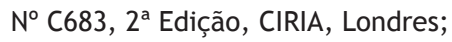

Draper, L. e Blakey, A. (1969) - Waves at Mersey Bar Light Vessel. Internal Report A.37, National Institute of Oceanography, Wormley, Reino Unido;

FoRTES, C.J.E.M. (2002) - Transformações Não-lineares de Ondas em Zonas Portuárias. Análise pelo Método dos Elementos Finitos. Tese de Doutoramento, Engenharia Mecânica, Universidade Técnica de Lisboa;

Hawkes, P.J., Bagenholm, C., Gouldby, B.P. e Ewing, J. (1997) - Swell and Bi-Modal Wave Climate Around the Coast of England and Wales. Relatório SR 409, HR Wallingford, Reino Unido; 
Hawkes, P. e Svensson, C. (2005) - Dependence Mapping and Best Practice. Relatório Técnico FD2308/TR1, Defra/Environment Agency, Londres;

HEDGES, T.S. e REIS, M.T. (2004) - "Accounting for random wave run-up in overtopping predictions". Maritime Engineering, Proc. ICE, Vol. 157(3), p. 113-122;

Hedges, T.S. e ReIs, M.T. (1998) - "Random wave overtopping of simple seawalls: a new regression model". Water, Maritime \& Energy Journal, Proc. ICE, Vol. 130(1), p. 1-10;

Hedges, T.S. e Shareef, M. (2003) - "Predicting seawall overtopping by bimodal seas". Proc. 28th Coastal Engineering Conference, ed. J.M. Smith, World Scientific, Singapura, Vol. 2, p. 2153-2164;

MelBy, J.A. (1999) - Damage Progression on RubbleMound Breakwaters. Technical Report CHL99-17, US Army Corps of Engineers Waterways Experiment Station, Vicksburg, EUA;

Melby, J.A. e KobayASHI, N. (1999) - "Damage progression and variability on breakwaters trunks". Proc. Coastal Structures '99, ed. I. Losada, A.A. Balkema, Roterdão, p. 309-315;

OWEN, M.W. (1980) - Design of Seawalls Allowing for Wave Overtopping. Relatório EX 924, Hydraulics Research Station, Reino Unido;

OWEn, M.W. (1983) - "The hydraulic design of seawall profiles". Proc. Shoreline Protection Conference, Institution of Civil Engineers, Londres, p. 185-192;

PALISADE CORPORATION (2002) - Guide to Using @ Risk: Risk Analysis and Simulation Add-In for Microsoft Excel - Version 4.5. Palisade Corporation, Nova York;

PALISADE CORPORATION (1994) - Risk Analysis and Simulation Add-In for Microsoft Excel or Lotus 1-2-3: Windows Version Release 3.1 User's Guide. Palisade Corporation, Nova York;

PUERTOS DEL ESTADO (2002) - R.O.M.-0.0. General Procedure and Requirements in the Design of Harbor and Maritime Structures. Part I: Recommendations for Maritime Structures. Technical Report, Puertos del Estado, Spain;

RACKWItZ, R. e FiesSleR, B. (1978) - "Structural reliability under combined random load sequences". Computers \& Structures, Vol. 9, p. 489-494;

REIS, M.T. (1998) - Probabilistic Assessment of the Safety of Coastal Structures. Tese para a obtenção do grau de Doctor in Philosophy, Departamento de Engenharia Civil, Universidade de Liverpool, Reino Unido;

ReIS, M.T., Hedges, T.S., Williams, A. e Keating, K. (2005) - “Determining seawall crest levels using risk analysis methodology". Proc. Coastal Engineering VII, Modelling, Measurements, Engineering and Management of Seas and Coastal Regions, Algarve, 13 a 15 de Abril de 2005, eds. C.A. Brebbia e M. de Conceição Cunha, WIT Press, Southampton, Reino Unido, p. 261-270;

Salin, B.A. (1989) - Probabilistic Properties of Wave Climates. Tese para a obtenção do grau de Doctor in Philosophy, Departamento de Engenharia Civil, Universidade de Liverpool, Reino Unido;

SHORE PROTECTION MANUAL (1984) - 4th ed., U.S. Army Engineer Waterways Experiment Station, U.S. Government Printing Office, Washington, EUA;

SmITH, W.G., Kobayashi, N. e Kaku, S. (1992). "Profile changes of rock slopes by irregular waves". Proc. 23rd Coastal Engineering Conference, Vol. 2, ASCE, p. 1559-1572;

SousA, I.A. (2007) - Evolução do Dano do Manto Protector de Quebra-mares de Taludes. Dissertação apresentada para satisfação parcial do requisitos para a atribuição do grau de Mestre em Engenharia Mecânica pela Universidade Técnica de Lisboa, Instituto Superior Técnico, Lisboa;

SousA, I.A. (2003) - Verificação da Segurança à Estabilidade do Manto de Quebra-mares de Taludes Utilizando Métodos Probabilísticos de Nível II. Trabalho final do curso de licenciatura em Engenharia Civil pela Universidade Técnica de Lisboa, Instituto Superior Técnico, Lisboa;

Sousa, I.A.; Santos, J.A. e Reis, M.T. (2005) "Dimensionamento do manto de quebra-mares de talude utilizando métodos probabilísticos de nível II”. Revista Recursos Hídricos, APRH, Vol. 26(1), p. 47-58;

USACE (2003) - Coastal Engineering Manual. Vicksburg, Mississippi (USA), Coastal \& Hydraulics Laboratory, U.S. Army Engineer Research and Development Center;

VAn der Meer, J. W. (1988) - Rock Slopes and Gravel Beaches Under Wave Attack. Ph.D. Thesis, Delft University of Technology, Holanda.

VAn der Meer, J.W. (2002) - Wave Run-Up and Overtopping at Dikes. TAW Technical Report, Technical Advisory Committee on Flood Defence, Delft, Holanda;

VAn der Meer, J.W. e Janssen, J.P.F.M. (1995) - "Wave run up and wave overtopping at dikes". Wave Forces on Inclined and Vertical Wall Structures, eds. N. Kobayashi e Z. Demirbilek, ASCE, Nova York, p. 1-27. 